\title{
Subclinical hypothyroidism: to treat or not to treat?
}

\section{Robin P Peeters ${ }^{1}$ and Juan P Brito ${ }^{\mathbf{2}}$}

'Department of Internal Medicine, Erasmus MC Academic Center for Thyroid Disease, Erasmus MC, Rotterdam, The Netherlands and ${ }^{2}$ Mayo Clinic, Knowledge and Evaluation Research Unit in Endocrinology (KER_Endo), Division of Endocrinology, Diabetes, Metabolism and Nutrition, Department of Medicine, Rochester, USA
Correspondence should be addressed to R P Peeters

Email

r.peeters@erasmusmc.nl

\begin{abstract}
There is controversy on the treatment of subclinical hypothyroidism $(\mathrm{SCH})$. While a number of guidelines from professional societies recommend treatment of SCH based on TSH levels, age, and presence of comorbidities, a recent guideline issued a recommendation against thyroid hormone treatment in adults with $\mathrm{SCH}$. In this debate article, we explore this controversy by presenting two points of view about $\mathrm{SCH}$ and its treatment. Treatment of patients who are pregnant or trying to become pregnant will not be discussed.
\end{abstract}

\section{Introduction}

Up to $12 \%$ of the adult population has subclinical hypothyroidism (SCH) (1, 2). SCH is a biochemical diagnosis, defined as an elevated serum thyroid-stimulating hormone (TSH) with normal circulating thyroid hormone levels; about $90 \%$ of all patients with SCH have TSH levels between 4 and $10 \mathrm{mIU} / \mathrm{L}(3,4)$. SCH can be transient due to recovery from illness or acute thyroid inflammation, whereas the persistent form of SCH is most likely due to autoimmune thyroid disease (5). For them, $\mathrm{SCH}$ represents a mild form of thyroid failure, with few patients progressing to overt hypothyroidism $(5,6)$. Patients with SCH may experience non-specific symptoms suggestive of overt hypothyroidism (e.g. tiredness, fatigue, and cold intolerance) $(7,8)$. Studies have reported higher rates of cognitive dysfunction, depression, and anxiety among adults with SCH compared to euthyroid adults $(9,10)$. Yet, the association between $\mathrm{SCH}$ and symptoms remains unclear; only $10 \%$ of patients with these symptoms have $\mathrm{SCH}$ and $\sim 25 \%$ of people with normal thyroid function report similar symptoms (11).

It is unclear whether patients with $\mathrm{SCH}$ should receive levothyroxine. Experts make recommendations for and against treatment. For example, using the same body of evidence, a number of guidelines recommend treatment of SCH based on TSH levels, age, and presence of comorbidities $(12,13)$, while a recent guideline issued a strong recommendation against thyroid hormones in adults with SCH (14). At the core of this controversy is the lack of pragmatic clinical trials enrolling patients likely to benefit from therapy.

In this article, we explore this controversy by presenting two points of view about $\mathrm{SCH}$ and its treatment. To this end, we will focus our arguments on those patients with SCH in whom levothyroxine therapy is considered. To illustrate that there is a consensus on the treatment of $\mathrm{SCH}$ in the majority of cases, we will briefly start with two cases in which we agree regarding treatment. The debate will then focus on the third case. In this debate article, we will not address the role of treatment for patients with transient SCH or patients who are pregnant or trying to become pregnant.

\section{Case A}

A 62-year-old woman presents to the outpatient clinic with complaints of fatigue and difficulty concentrating.

Published by Bioscientifica Ltd. 
She has a history of episodes with depressive symptoms, but feels that her current complaints are different. Her family history is negative for thyroid disease. General laboratory tests are normal, except a slightly elevated TSH ( $5.9 \mathrm{mU} / \mathrm{L}$, reference range: $0.4-4.3 \mathrm{mU} / \mathrm{L}$ ), whereas FT4 is normal (19pmol/L, reference range: $11-25 \mathrm{pmol} / \mathrm{L})$.

\section{Should she be treated with LT4, if a repeat TSH is similar?}

We found several reasons for not offering levothyroxine therapy. The first is that the patient may not have SCH. Her mildly elevated TSH values may be normal if we consider a TSH value range adjusted for her age. In addition, her FT4 of 19 pmol/L makes a relation with her complaints even more unlikely. The decision not to offer levothyroxine therapy at this moment will not be altered if the TPO antibodies are positive upon repeat testing, although patients with TPO antibodies have a two-fold increased risk of progression to overt hypothyroidism. Several randomized trials have shown that levothyroxine therapy will provide little or no benefit for patients like her. Given her past medical history, a potential plan of care is to review with her primary care or psychiatrist the possible association of symptoms with depression or antidepressant treatment.

\section{Case B}

A 68-year-old woman presents to the outpatient clinic with weight gain, constipation, cold intolerance and fatigue. Except mild rheumatoid arthritis, she has no other comorbidities. Both her daughters have been diagnosed with thyroid disease (Graves' disease in one, Hashimoto's thyroiditis in the other). Her TSH was 2.3 $\mathrm{mIU} / \mathrm{L}$ when tested 6 years ago. Current laboratory testing shows no abnormalities in the general lab, but a clearly elevated TSH of $14 \mathrm{mU} / \mathrm{L}$ with a normal FT4 (12 pmol/L, reference range: $11-25 \mathrm{pmol} / \mathrm{L}$ ). Her TPO-antibodies are positive, according to the cut-off provided by the assay manufacturer.

\section{Should she be treated with LT4, if a repeat TSH is similar?}

We would treat this patient with LT4. The main reason is that there is a very high chance that she will develop overt hypothyroidism in the upcoming period. Although the overall risk of progression to overt hypothyroidism is about $2-6 \%$ per year, the risk is highest in those with higher TSH elevations, with thyroid peroxidase autoantibodies (TPOab's), female patients and those with low-normal FT4 levels
$(15,16,17)$. So, she is already symptomatic with proven AITD and will very likely develop overt hypothyroidism in the next few years. Why wait with LT4 therapy until she is fully hypothyroid with even more complaints? A second argument may be that epidemiological evidence shows that a TSH $>10 \mathrm{mIU} / \mathrm{L}$ is associated with a higher risk of coronary heart disease events and mortality. Although we lack adequately powered RCTs that study the effects of LT4 treatment in SCH, observational studies suggest a lower all-cause mortality in LT4 treated patient younger than $65 / 70$ years $(4,18,19)$. However, these observational studies are subject to selection bias and confounding and must be interpreted with caution.

\section{Case C}

A 61-year-old woman presents to the outpatient clinic with fatigue and weight gain. She has no comorbidities. Her family history for thyroid disease is unknown. Both her parents died of myocardial infarction in recent years. Laboratory testing shows an LDL cholesterol of 3.2 $\mathrm{mmol} / \mathrm{L}$, which was $2.7 \mathrm{mmol} / \mathrm{L} 1$ year ago. There are no abnormalities in the general lab, but her TSH is $8.2 \mathrm{mIU} / \mathrm{L}$ with a normal FT4 (13 pmol/L, reference range: 11-25 pmol/L). Her TPO-antibodies are not measured.

Should she be treated with $L T 4$, if a repeat TSH remains this high?

\section{Robin P Peeters}

I would consider LT4 treatment in this patient, after carefully excluding other causes of her complaints. Particularly if the repeat TSH increases further and the FT4 remains in this low-normal range. However, her symptoms are aspecific and have been reported in many other conditions as well (11). For that reason, I will discuss with her that we will stop treatment if no clear improvement of symptoms occurs after 6 months (20). Two recent RCTs showed no beneficial effect on symptoms in elderly patients $(21,22)$, but both studies mainly included very mild SCH (median TSH of 5.7 and $5.8 \mathrm{mIU} / \mathrm{L}$, respectively) with a mean age of 74 and 84 years, respectively, and normal symptom scores at baseline. I will try to obtain more circumstantial evidence pointing toward other symptoms of hypothyroidism. This information is currently lacking, except may be an increase in LDL. Together with the repeat TSH and FT4 after 2-3 months, I would measure TPO antibodies. Like patients with a low-normal FT4 and symptoms of hypothyroidism, patients with TPO antibodies have a two and three-fold 
higher risk of progression to overt hypothyroidism (15, 17). The fact that she has a positive family history for cardiovascular disease does not influence my decision. Although several small-scale RCTs have shown beneficial effects of LT4 treatment on cardiovascular risk factors and lipid profile $(4,23,24)$, this does not justify treatment since data on clinical outcome are lacking. If there would be an indication to lower her lipid levels, I would prefer to give a statin over LT4 if the statin is well-tolerated (muscle aches, CPK increase).

Altogether, I feel that there are arguments in favor of treatment in this patient with a TSH of $8.2 \mathrm{mIU} / \mathrm{L}$ and a low-normal FT4, particularly in case of more suggestive evidence of thyroid disease (i.e. TPOab positivity) or additional clinical symptoms of hypothyroidism. I would discuss those arguments with the patient. If she prefers treatment, but there is no clinical benefit, I will stop treatment after 6 months and switch to follow-up. Duration of follow-up depends on factors such as degree of TSH evaluation, symptoms, and patient's preferences. For this particular patient, given the symptoms and elevation of TSH, I would continue to favor a 6-month follow up.

\section{Juan P Brito}

I would not offer levothyroxine therapy up front, but rather use the following approach. After understanding more about her symptoms and how they affect her quality of life, I would begin to exclude conditions typically associated with them. I would also describe to her what seems to be the only abnormality in her test results, and what it means for her to have an elevated TSH value, particularly the uncertainty about the association between the results and symptoms. Then, I would present different options, including (1) observation and close monitoring, (2) therapies targeting symptoms such as cognitive training for fatigue and weight loss interventions, and (3) initiation of levothyroxine. I would discuss the pros and cons of each care plan and how each fits her needs and values. For instance, regarding levothyroxine, I would explain what we know about the lack of effect that therapy has on her symptoms as well as the practical issues involved with thyroid replacement therapy (e.g. it must be taken away from food or multivitamins, frequent clinic appointments for monitoring with out-of-pocket and taking time off work to attend appointments). If the TSH lowering therapy becomes the option that makes sense for her situation, I would design a plan in which the lowest dose of thyroid replacement therapy is initiated to normalize TSH values and avoid side effects. Additionally, I would organize with the patient a follow-up time in which we would decide on treatment discontinuation if treatment had shown to lack benefits.

\section{Robin P Peeters for treatment}

\section{Part of the patients with SCH have true thyroid disease and should be treated with LT4}

Denying treatment to all patients with $\mathrm{SCH}$ leaves a subgroup of patients with true thyroid disease untreated, resulting in a poor quality of life and a condition associated with a worse prognosis.

\section{Subclinical hypothyroidism can be due to true thyroid disease}

Serum TSH and FT4 show substantial variability between healthy individuals, whereas the variability within a healthy individual is usually in a much narrower range (25). This points toward a unique individual set point of the hypothalamic-pituitary-thyroid (HPT) axis, and likely explains why a TSH of $10 \mathrm{mU} / \mathrm{L}$ can be accompanied by normal FT4 in one, but by decreased FT4 in the other. In this respect, SCH can be interpreted as a mild form of thyroid failure, due to autoimmune thyroid disease in the majority of cases (20). This is supported by the high progression rate to overt hypothyroidism in patients with a clearly elevated TSH $(15,16)$. The severity of SCH is usually based on the level of TSH elevation, with a commonly used cut-off of $10 \mathrm{mU} / \mathrm{L}$ to distinguish between mild and more severe SCH $(3,4,26)$. In patients $<70$ years, most guidelines from professional societies recommend treatment of $\mathrm{SCH}$ when the TSH $>10 \mathrm{mIU} / \mathrm{L}(1,13)$, whereas no routine treatment of $\mathrm{SCH}$ is recommended in patients with a TSH $<10 \mathrm{mIU} / \mathrm{L}$. Despite these conservative recommendations, prescriptions for levothyroxine have increased substantially in the last decade (27). This seems mainly due to the treatment of mild $\mathrm{SCH}$, since the prevalence of overt hypothyroidism is stable and up to $90 \%$ of patients with SCH have a TSH $<10 \mathrm{mU} / \mathrm{L}$ $(3,11)$. Against current recommendations, one-third of adults with $\mathrm{SCH}$ are offered treatment after a single TSH testing (28). Not all of these patients will have true $\mathrm{SCH}$ as TSH levels can be temporarily elevated due to other causes such as non-thyroidal illness or thyroiditis (29). Altogether, this suggests poor adherence to current guidelines recommending against routine treatment $(1,13)$. 
In the context of increased levothyroxine prescriptions, the current guidelines have recently been challenged by a Rapid Recommendation published in the British Medical Journal (14), reporting 'a strong recommendation against thyroid hormone treatment in adults with $\mathrm{SCH}$ and a TSH $<20 \mathrm{mIU} / \mathrm{L}^{\prime}$. Although it is important to decrease this overuse of levothyroxine in patients without a clear treatment indication, a recommendation not to treat any patient with $\mathrm{SCH}$ and a TSH $<20 \mathrm{mIU} / \mathrm{L}$ will leave the group of symptomatic patients with true thyroid disease untreated. This Rapid Recommendation was largely based on a systematic review and meta-analysis reporting no clear benefit of levothyroxine treatment for multiple outcomes (23). Whereas the authors of the systematic review acknowledged that the results of their meta-analyses 'may not be generalizable to patients with $\mathrm{SCH}$ and a TSH $>10 \mathrm{mIU} / \mathrm{L}^{\prime}$, the authors of the Rapid Recommendation used the same evidence to formulate a recommendation against treatment in all patients with a TSH $<20 \mathrm{mIU} / \mathrm{L}$ (14). This cut-off has subsequently been challenged by many authors, including a recent analysis of the mean pooled baseline TSH values of patients included in the meta-analyses by Feller. This showed that the TSH ranged from 6.4 to $7.3 \mathrm{mIU} / \mathrm{L}$, thereby confirming the lack of data on more severe SCH (30). Although the meta-analysis by Feller shows that treatment of very mild $\mathrm{SCH}$ is not beneficial in the vast majority of patients, we lack tools to identify the subgroups of patients that will benefit. In addition, we lack robust evidence on more severe SCH (i.e. TSH > $10 \mathrm{mIU} / \mathrm{L}$ ). Particularly patients with more severe $\mathrm{SCH}$ are at risk of thyroid failure and to develop complications. Until we have better data for these subgroups, the decision to treat $\mathrm{SCH}$ is not a permanent choice between yes and no. In addition to the TSH, patient context should be taken into account so that treatment will not incorrectly be denied to symptomatic patients with clear $\mathrm{SCH}$.

\section{Patients with SCH have a poor quality of life and a worse prognosis}

Patients with $\mathrm{SCH}$ more often report symptoms of overt hypothyroidism than age-matched controls, although symptoms are usually milder than in overt hypothyroidism. Number and severity of symptoms increase with higher TSH concentrations. Decreased quality of life, more depressive symptoms, decreased cognitive function and memory have been reported in patients with $\mathrm{SCH}$, but not in all studies $(11,24,31,32)$. This is likely due to the selection of patients (biochemical screening of a population vs a selection of patients with pre-existing symptoms, age of the patients, the severity of $\mathrm{SCH}$, etc). Also, other symptoms associated with overt hypothyroidism such as fatigue, muscle weakness, weight gain, cold intolerance, and constipation occur more frequently in patients with SCH than in the normal population $(4,5)$. In those patients with $\mathrm{SCH}$ due to a mild form of thyroid failure, it is highly likely that the symptoms are causally related.

As discussed previously, patients with $\mathrm{SCH}$ have an increased risk of progression to overt hypothyroidism, with the highest risk in those with higher TSH elevations, with thyroid peroxidase autoantibodies (TPO-ab's) and with low-normal FT4 levels $(15,16,17)$. Given the importance of thyroid hormone for various organ systems, the negative consequences of long-term SCH can be expected. This has best been studied for the cardiovascular system. An individual participant data-based meta-analysis from 11 prospective cohort studies ( $n>55000$ participants) showed an increased risk of fatal and non-fatal coronary heart disease events, which further increased with higher TSH levels (3). SCH, particularly at TSH levels $>7 \mathrm{mIU} / \mathrm{L}$, has also been associated with congestive heart failure and fatal stroke in similar individual participant based metaanalyses $(33,34)$. SCH is also associated with a worse lipid profile and surrogate markers of cardiovascular disease, but it is currently unclear if lipid metabolism or other mechanisms mediate these effects on cardiovascular disease.

It is highly likely that patients with morbidities due to $\mathrm{SCH}$ will benefit from LT4 treatment

There is no doubt that the treatment of overt hypothyroidism improves clinical signs and symptoms of hypothyroidism (35). It is therefore highly likely that in those patients with $\mathrm{SCH}$ due to a mild form of thyroid failure (milder) signs and symptoms of hypothyroidism will improve as well. Multiple studies have shown a continuous relationship between FT4 concentrations, even within the normal range, and thyroid-related endpoints, such as cardiovascular disease and risk of diabetes (35). It isvery unlogical to assume that a patient with a TSH of $12 \mathrm{mIU} / \mathrm{L}$ and an FT4 of $10 \mathrm{pmol} / \mathrm{L}$ (11-25 $\mathrm{pmol} / \mathrm{L}$ ) will benefit from LT4, whereas a patient with a TSH of $12 \mathrm{mIU} / \mathrm{L}$ and an FT4 of $11.5 \mathrm{pmol} / \mathrm{L}$ will not.

However, patients with other causes of an elevated TSH (i.e. recovery from non-thyroidal illness, recovery from thyroiditis, specific types of medication, assay interference due to for example macro-TSH or heterophilic 
antibodies, severe obesity) will not benefit from treatment (20). It is, therefore, essential to make a distinction between true subclinical hypothyroidism and other causes of isolated hyperthyrotropenemia. This is even more important in elderly patients, since a widening of the reference range has been described in elderly persons living in regions with historical iodine sufficiency as part of the physiologic adaptation to aging $(36,37)$. For practical reasons, virtually all studies investigating the treatment of SCH use a purely biochemical diagnosis, without using an age-adjusted reference range for TSH for example (23). This may have contributed to the normal quality of life at baseline in subjects participating in the TRUST and IEMO trials $(21,22)$. For the above-mentioned reasons, it is essential to clearly establish a good clinical diagnosis and use the full patient context to interpret the biochemical results. This is particularly relevant in case of a mildly elevated TSH, since the majority of other causes mentioned above cause only a slightly elevated TSH.

\section{A word of caution}

Although LT4 treatment is relatively cheap and often considered harmless, a substantial proportion of hypothyroid patients treated with LT4 continue to have TSH levels outside the reference range in day-today clinical practice $(28,38)$. Five years after initiation of LT4 therapy, more than $10 \%$ of patients still have TSH levels > $10.0 \mathrm{mIU} / \mathrm{L}$ and almost $6 \%$ of patients have suppressed TSH levels < $0.1 \mathrm{mIU} / \mathrm{L}$ (28). Whereas undertreatment will mainly result in the lack of a possible beneficial effect, overtreatment (a suppressed TSH) should clearly be avoided since this is consistently associated with an increased risk of atrial fibrillation, osteoporosis and fractures, especially in the elderly $(2,39)$. Although the two most recent RCTs on SCH in the elderly, with a clear treatment protocol, showed no evidence for overtreatment or harms $(21,22)$, treatment should be stopped when there is a lack of clear clinical benefit.

\section{Conclusion}

Prescription rates of LT4 have increased substantially in recent years, without any evidence for an increased prevalence of overt hypothyroidism. This seems to be mainly due to treatment of mild SCH with a TSH $<10$ $\mathrm{mIU} / \mathrm{L}$, and due to immediate treatment after a single elevated TSH. This demonstrates that adherence to current guidelines from scientific societies should be improved
$(1,13)$, but is no argument to relentlessly raise the TSH cut-off from 10 to $20 \mathrm{mIU} / \mathrm{L}$. Just like the available evidence does not justify the treatment of all patients with $\mathrm{SCH}$, it does not justify that no patients with $\mathrm{SCH}$ should be treated either. Based on the available evidence, physicians should aim to identify those patients who are likely to benefit from treatment, by considering all relevant contextual factors such as symptoms, comorbidities, patient preference, and safety issues. So I am not advocating treatment of all patients with $\mathrm{SCH}$, but only in those with a TSH $>10 \mathrm{mIU} / \mathrm{L}$ or in those with a TSH between 7 and $10 \mathrm{mIU} / \mathrm{L}$ and a likely relation of the SCH with the patients' complaints. In those patients, a 6-month trial of LT4 treatment can be considered and discussed with the patient. If there is no clear clinical benefit, treatment should be stopped after this period.

\section{Juan P Brito against treatment}

\section{There is little or no benefit of levothyroxine for patients with $\mathrm{SCH}$}

For patients with $\mathrm{SCH}$ to be better off with treatment, treatment must improve their quality of life and/or their prognosis.

\section{Symptoms and quality of life}

The body of randomized trial evidence has ruled out moderate-to-large symptomatic benefits with treatment for SCH (23). These randomized trials have included mostly women (46-100\%) with a mean age of 50 (range 32-74), mean TSH at baseline of 6.6 (range 4.4-12.8 $\mathrm{mU} / \mathrm{L}$ ), and mild to moderate burden of symptoms. A meta-analysis of these trials showed no difference in hypothyroid symptoms (16.7 vs 16.5 ) or fatigue/tiredness (28.6 vs 29) as assessed using the ThyPRO self-reported instrument (scale 0-100, lower better), or in healthrelated quality of life, depression, cognitive function, or muscle strength (23). Most of the evidence came from the TRUST trial which included 737 participants 65 and older, with a mean TSH value of $6.4 \pm 2 \mathrm{mU} / \mathrm{L}$, a mean ThyPRO hypothyroid symptom score at baseline of 17 , and a mean tiredness score of 25 (22). A sensitivity analysis showed that meta-analytic estimates were not dependent on the inclusion of this trial in the pooled estimates (40). These results are directly applicable to the vast majority of older patients with SCH contemplating treatment (3). A recent pooled analysis of two trials of patients 80 years 
or older with a mean TSH of $6.4 \mathrm{mU} / \mathrm{L}$ also showed no significant improvement in hypothyroid symptoms or fatigue with treatment, extending the applicability of the evidence to the elderly (21). Clinical trials on the efficacy of levothyroxine treatment provided results that may not apply to the care of younger people with $\mathrm{SCH}$, in whom even mild TSH value elevation is considered abnormal. Few trials included only patients younger than 50 and none of these trials assessed the impact of treatment on quality of life in this subgroup.

\section{Prognosis - cardiovascular outcomes}

Several observational studies have shown an association between severe forms of SCH (TSH $\geq 10 \mathrm{mU} / \mathrm{L}$ ) and cardiovascular disease, particularly in patients younger than 65 and those with a high baseline cardiovascular risk $(3,34,41)$. The strength of this association is, however, limited by misclassification of cases (many studies likely included only patients with transient TSH elevation), unmeasured confounders, and non-accounted for interventions that impact cardiovascular risk. Although there are no randomized clinical trials with sufficient power to examine the impact of thyroid hormone therapy on cardiovascular events, the TRUST study found that treatment of SCH did not impact the incidence of cardiovascular events within 1 year after initiation of therapy, HR 0.89 (95\% CI, 0.47-1.69). Yet, confidence in these estimates should be low, given the low prevalence of events during follow-up (22).

Inconsistent observational evidence has suggested a possible association of high TSH levels with worse clinical outcomes in patients with heart failure. An individual patient data meta-analysis of 25390 participants from six prospective cohorts in the United States and Europe, however, found no increased risk of incident heart failure in patients with TSH values between 4.5 and $9.9 \mathrm{mU} / \mathrm{L}$ (34). No randomized trial of levothyroxine in patients with SCH and heart failure has been conducted. There is also a reported association of $\mathrm{SCH}$ with cardiovascular risk factors; use of levothyroxine therapy may decrease these abnormalities. A randomized, cross-over study of patients with SCH (mean TSH $6.6 \mathrm{mU} / \mathrm{L}$ ) found that compared to placebo, $100 \mu \mathrm{g}$ of levothyroxine reduced triglycerides from 232 to $220 \mathrm{mg} / \mathrm{dL}$; low-density lipoprotein cholesterol from 143 to $131 \mathrm{mg} / \mathrm{dL}$, and waist-to-hip ratio from 0.83 to 0.81 (24). Although these changes were statistically significant, it is unclear if there are of clinical relevance.
Prognosis - progression to over hypothyroidism

Large observational studies of the natural history of SCH have found that about $2 \%$ (in the absence of TPOantibodies) and 4\% (in the presence of TPO-antibodies) of patients with SCH and mild TSH elevation (4-10 mU/L) progress to overt hypothyroidism every year, while $60 \%$ see their TSH levels return to the normal range over 5 years without treatment $(5,6)$. These estimates strongly suggest that only a minority of patients with SCH will progress and most will improve without treatment. If we were to treat 100 patients with SCH with TSH elevations between 4 and $10 \mathrm{mU} / \mathrm{L}$, we will potentially avoid the progression to hypothyroidism for $2-4$ patients, but we will unnecessarily treat the rest.

\section{Potential harms of treatment}

In addition to producing no ostensible benefit, levothyroxine use may harm patients. Levothyroxine treatment requires modification of daily habits - for example, dosing 30-60 min before a meal, monitoring of effects, and frequent dose titration and clinic and laboratory visits. Also, treatment costs \$1600/year, and up to $\$ 4100 /$ year for patients requiring three or more dose adjustments (42). Although these (42) challenges could be mitigated in relatively healthy patients without affordability issues, they could be substantial in elderly patients with SCH. Elderly patients are at higher risk of multimorbidity and polypharmacy, and many struggle financially. Adding levothyroxine therapy to this group of patients could increase the burden of treatment, which in turn may lead to nonadherence and poor health outcomes $(43,44)$. Levothyroxine treatment may also expose patients to high thyroid hormone levels. Among patients older than 65 years taking levothyroxine, 40-50\% had a TSH concentration below $0.45 \mathrm{mIU} / \mathrm{L}$ during the follow up $(38,45,46)$. The Framingham study found that for people 60 years and older, a low TSH value was associated with a 3-fold increase in the risk of atrial fibrillation over a 10-year period compared to people with normal levels of TSH (45).

Levothyroxine overuse also burdens society. In the United States, the number of prescriptions for levothyroxine increased from 97 million in 2007 to 120 million in 2014; similarly, levothyroxine has become the third most prescribed drug in the UK $(27,47)$. Given that the prevalence of overt hypothyroidism has remained 
stable, treatment for SCH must account for this increase in levothyroxine use. For instance, a population-based study showed that prevalence of treated SCH increased by $64 \%$ in women, and by $54 \%$ in men in 1995 and between 2006 and 2008 (48). Once levothyroxine is started for patients with $\mathrm{SCH}$, about $90 \%$ continue levothyroxine indefinitely (28). The lack of benefit of levothyroxine treatment for patients with $\mathrm{SCH}$ and the potential harm of treatment strongly suggest that many patients with $\mathrm{SCH}$ are overtreated.

\section{How to do better}

The existing evidence, somehow, has not reduced clinicians' enthusiasm for treating patients with $\mathrm{SCH}$. Besides issues of treatment effectiveness and harm, additional drivers of the decision to treat $\mathrm{SCH}$ may include: the lack of alternative explanations for symptoms (e.g. fatigue), the need for a therapeutic trial, presence of thyroid autoimmunity, additional comorbidities such as obesity or depression, or the impact of guidelines with recommendations at odds with the extant evidence reviewed here. The American Thyroid Association (ATA) and the American Association of Clinical Endocrinologists (AACE), for example, recommend that 'treatment based on individual factors for patients with TSH levels between the upper limit of a given laboratory's reference range and $10 \mathrm{mIU} / \mathrm{L}$ should be considered particularly if they have symptoms suggestive of hypothyroidism, positive (anti) thyroperoxidase antibodies, or evidence of atherosclerotic cardiovascular disease (or) heart failure, or have associated risk factors for these diseases' (12). Following this recommendation would result in treating $92 \%$ of all women with $\mathrm{SCH}$. It remains unclear what research is needed to align clinical practice with the existing evidence of lack of benefit and potential harm of levothyroxine.

\section{Avoid screening and reduce overtesting for thyroid dysfunction}

Although there are limitations with the evidence and there is still uncertainty about whether levothyroxine treatment benefits subgroups of $\mathrm{SCH}$ patients, the majority of patients with $\mathrm{SCH}$ receive little or no benefit from levothyroxine treatment. This overuse of levothyroxine starts with the overtesting with TSH assays, particularly in asymptomatic patients. For instance, one study found that $71 \%$ of 135243 persons (aged 20-year or older) without known thyroid disease had their TSH levels measured at least once over a 2-year period (49). In the United Kingdom, up to $25 \%$ of all adults receive routine thyroid function testing each year (28). There is no known benefit of such screening for thyroid dysfunction such that the United States Preventative Services Task Force and the Canadian Task Force on Preventive Health Care have both issued recommendations against thyroid dysfunction screening (50). The implementation of these recommendations has the potential to reduce TSH overtesting.

\section{Avoid misdiagnosis of $\mathrm{SCH}$}

Besides reducing the number of patients undergoing $\mathrm{SCH}$ screening, significant effort is needed to avoid SCH misdiagnosis. $\mathrm{SCH}$ diagnosis is based on a TSH test, the values of which are influenced by normal biological variations, medications, and analytical assay interference. A study following outpatients without thyroid disease over 5 years found that $62 \%$ of TSH values normalized without any intervention (6). To overcome this TSH variability, it is recommended that patients with one abnormal TSH value receive another test after a few weeks to confirm SCH (1). Despite this concern for false-positive results, one-third of patients receive treatment after only one abnormal TSH test result (28). Clinicians, including endocrinologists, need to understand the pitfalls of TSH testing to improve $\mathrm{SCH}$ diagnosis and avoid unnecessary treatment. Another factor that drives the misdiagnosis of SCH are euthyroid outliers (51); patients in whom high TSH could be still considered part of the normal range for their age. To correctly classify these patients, the TSH reference range may need to be tailored based on age group (52). In fact, some guidelines suggest increasing the upper limit of normal TSH from 5 to $6 \mathrm{mU} / \mathrm{L}$ to account for these patients $(1,13,53)$. Based on the premises of potential SCH misdiagnosis several studies have aimed to assess the effect of levothyroxine discontinuation on $\mathrm{SCH}$ patients. These studies have consistently showed that $30-60 \%$ of the patients (with and without TPO-antibodies) remained euthyroid after levothyroxine withdrawal $(54,55,56,57)$.

\section{Conclusion}

There is significant evidence that supports the notion that levothyroxine has limited value for patients with $\mathrm{SCH}$, and that its use has been increasing over time as a reflection of more $\mathrm{SCH}$ screening, $\mathrm{SCH}$ misdiagnosis, and lack of effective approaches to manage non-specific symptoms. Although this evidence suggests that levothyroxine should not be offered as treatment to these patients, it is 
possible that uncertainty about the nature of symptoms could lead to a brief levothyroxine n-of-1 treatment trial.

\section{Overall conclusion Juan $P$ Brito and Robin P Peeters}

\section{Manage uncertainty and therapeutic restrain}

How to care for a patient with SCH and mild symptoms remains puzzling. Failure to act and correct the laboratory abnormality may be perceived as uncaring, while acting on a laboratory test without assisting the patient and palliating their symptoms may be truly so. In order to stop the rise in unnecessary levothyroxine prescriptions, adherence to current guidelines from scientific societies should be improved and clinicians may need to become more expert in the management of symptoms without a clear pathological correlate, particularly in the case of mild elevations in TSH.

In patients younger than 70 years with a $\mathrm{TSH}>10$ $\mathrm{mIU} / \mathrm{L}, \mathrm{SCH}$ is a form of thyroid failure due to autoimmune thyroid disease in the vast majority of cases. It is for that reason that current ETA and ATA guidelines recommend (consideration of) treatment, particularly in the case of clear symptoms.

In the absence of alternative courses of action, and after reviewing the evidence described above, patient and clinician may opt to conduct a 6-month therapeutic trial, an n-of-1 trial, with the lowest dose of levothyroxine needed to normalize TSH. Symptoms should be reassessed periodically and treatment discontinued if and when no benefit becomes evident.

\section{Declaration of interest}

R P Peeters has received lecture fees from IBSA and Merck. J P Brito reports no conflicts of interest.

\section{Funding}

This research did not receive any specific grant from any funding agency in the public, commercial or not-for-profit sector.

\section{References}

1 Jonklaas J, Bianco AC, Bauer AJ, Burman KD, Cappola AR, Celi FS, Cooper DS, Kim BW, Peeters RP, Rosenthal MS et al. Guidelines for the treatment of hypothyroidism: prepared by the American Thyroid Association task force on thyroid hormone replacement. Thyroid 201424 1670-1751. (https://doi.org/10.1089/thy.2014.0028)

2 Cooper DS \& Biondi B. Subclinical thyroid disease. Lancet 2012379 1142-1154. (https://doi.org/10.1016/S0140-6736(11)60276-6)

3 Rodondi N, Den Elzen WP, Bauer DC, Cappola AR, Razvi S, Walsh JP, Åsvold BO, Iervasi G, Imaizumi M, Collet TH et al. Subclinical hypothyroidism and the risk of coronary heart disease and mortality. JAMA 2010304 1365-1374. (https://doi.org/10.1001/ jama.2010.1361)

4 Biondi B, Cappola AR \& Cooper DS. Subclinical hypothyroidism: a review. JAMA 2019322 153-160. (https://doi.org/10.1001/ jama.2019.9052)

5 Biondi B \& Cooper DS. The clinical significance of subclinical thyroid dysfunction. Endocrine Reviews 200829 76-131. (https://doi. org/10.1210/er.2006-0043)

6 Meyerovitch J, Rotman-Pikielny P, Sherf M, Battat E, Levy Y \& Surks MI. Serum thyrotropin measurements in the community: fiveyear follow-up in a large network of primary care physicians. Archives of Internal Medicine 2007167 1533-1538. (https://doi.org/10.1001/ archinte.167.14.1533)

7 Almeida C, Brasil MA, Costa AJL, Reis FA, Reuters V, Teixeira P, Ferreira M, Marques AM, Melo BA \& Teixeira LBdM. Subclinical hypothyroidism: psychiatric disorders and symptoms. Brazilian Journal of Psychiatry 200729 157-159. (https://doi.org/10.1590/ s1516-44462007000200013)

8 Hong JW, Noh JH \& Kim DJ. Association between subclinical thyroid dysfunction and depressive symptoms in the Korean adult population: the 2014 Korea National Health and Nutrition Examination Survey. PLoS ONE 201813 e0202258. (https://doi. org/10.1371/journal.pone.0202258)

9 Roberts LM, Pattison H, Roalfe A, Franklyn J, Wilson S, Hobbs FD \& Parle JV. Is subclinical thyroid dysfunction in the elderly associated with depression or cognitive dysfunction? Annals of Internal Medicine 2006145 573-581. (https://doi.org/10.7326/0003-4819-145-8200610170-00006)

10 Simonsick EM, Newman AB, Ferrucci L, Satterfield S, Harris TB, Rodondi N, Bauer DC \& Health ABC Study. Subclinical hypothyroidism and functional mobility in older adults. Archives of Internal Medicine 2009169 2011-2017. (https://doi.org/10.1001/ archinternmed.2009.392)

11 Canaris GJ, Manowitz NR, Mayor G \& Ridgway EC. The Colorado thyroid disease prevalence study. Archives of Internal Medicine 2000 160 526-534. (https://doi.org/10.1001/archinte.160.4.526)

12 Garber JR, Cobin RH, Gharib H, Hennessey JV, Klein I, Mechanick JI, Pessah-Pollack R, Singer PA, Woeber KA \& American Association of Clinical Endocrinologists and American Thyroid Association Taskforce on Hypothyroidism in Adults. Clinical practice guidelines for hypothyroidism in adults: cosponsored by the American Association of Clinical Endocrinologists and the American Thyroid Association. Thyroid 201222 1200-1235. (https://doi.org/10.1089/ thy.2012.0205)

13 Pearce SH, Brabant G, Duntas LH, Monzani F, Peeters RP, Razvi S \& Wemeau JL. 2013 ETA guideline: management of subclinical hypothyroidism. European Thyroid Journal 20132 215-228. (https:// doi.org/10.1159/000356507)

14 Bekkering GE, Agoritsas T, Lytvyn L, Heen AF, Feller M, Moutzouri E, Abdulazeem H, Aertgeerts B, Beecher D, Brito JP et al. Thyroid hormones treatment for subclinical hypothyroidism: a clinical practice guideline. BMJ 2019365 12006. (https://doi.org/10.1136/ bmj.12006)

15 Diez JJ, Iglesias P \& Burman KD. Spontaneous normalization of thyrotropin concentrations in patients with subclinical hypothyroidism. Journal of Clinical Endocrinology and Metabolism 2005 90 4124-4127. (https://doi.org/10.1210/jc.2005-0375)

16 Huber G, Staub JJ, Meier C, Mitrache C, Guglielmetti M, Huber P $\&$ Braverman LE. Prospective study of the spontaneous course of subclinical hypothyroidism: prognostic value of thyrotropin, thyroid reserve, and thyroid antibodies. Journal of Clinical Endocrinology and Metabolism 200287 3221-3226. (https://doi.org/10.1210/ jcem.87.7.8678)

17 Vanderpump MP, Tunbridge WM, French JM, Appleton D, Bates D, Clark F, Grimley Evans J, Hasan DM, Rodgers H \& Tunbridge F. The 
incidence of thyroid disorders in the community: a twenty-year follow-up of the Whickham Survey. Clinical Endocrinology 199543 55-68. (https://doi.org/10.1111/j.1365-2265.1995.tb01894.x)

18 Andersen MN, Olsen AM, Madsen JC, Faber J, Torp-Pedersen C, Gislason GH \& Selmer C. Levothyroxine substitution in patients with subclinical hypothyroidism and the risk of myocardial infarction and mortality. PLoS ONE 201510 e0129793. (https://doi.org/10.1371/ journal.pone.0129793)

19 Razvi S, Weaver JU, Butler TJ \& Pearce SH. Levothyroxine treatment of subclinical hypothyroidism, fatal and nonfatal cardiovascular events, and mortality. Archives of Internal Medicine 2012172 811-817. (https://doi.org/10.1001/archinternmed.2012.1159)

20 Peeters RP. Subclinical hypothyroidism. New England Journal of Medicine 2017376 2556-2565. (https://doi.org/10.1056/ NEJMcp1611144)

21 Mooijaart SP, Du Puy RS, Stott DJ, Kearney PM, Rodondi N, Westendorp RGJ, den Elzen WPJ, Postmus I, Poortvliet RKE, van Heemst $\mathrm{D}$ et al. Association between levothyroxine treatment and thyroid-related symptoms among adults aged 80 years and older with subclinical hypothyroidism. JAMA 2019322 1-11. (https://doi. org/10.1001/jama.2019.17274)

22 Stott DJ, Rodondi N, Kearney PM, Ford I, Westendorp RGJ, Mooijaart SP, Sattar N, Aubert CE, Aujesky D, Bauer DC et al. Thyroid hormone therapy for older adults with subclinical hypothyroidism. New England Journal of Medicine 2017376 2534-2544. (https://doi. org/10.1056/NEJMoa1603825)

23 Feller M, Snel M, Moutzouri E, Bauer DC, De Montmollin M, Aujesky D, Ford I, Gussekloo J, Kearney PM, Mooijaart S et al. Association of thyroid hormone therapy with quality of life and thyroid-related symptoms in patients with subclinical hypothyroidism: a systematic review and meta-analysis. JAMA 2018 320 1349-1359. (https://doi.org/10.1001/jama.2018.13770)

24 Razvi S, Ingoe L, Keeka G, Oates C, McMillan C \& Weaver JU. The beneficial effect of L-thyroxine on cardiovascular risk factors, endothelial function, and quality of life in subclinical hypothyroidism: randomized, crossover trial. Journal of Clinical Endocrinology and Metabolism 200792 1715-1723. (https://doi. org/10.1210/jc.2006-1869)

25 Andersen S, Pedersen KM, Bruun NH \& Laurberg P. Narrow individual variations in serum $\mathrm{T}(4)$ and $\mathrm{T}(3)$ in normal subjects: a clue to the understanding of subclinical thyroid disease. Journal of Clinical Endocrinology and Metabolism 200287 1068-1072. (https:// doi.org/10.1210/jcem.87.3.8165)

26 Surks MI, Ortiz E, Daniels GH, Sawin CT, Col NF, Cobin RH, Franklyn JA, Hershman JM, Burman KD, Denke MA et al. Subclinical thyroid disease: scientific review and guidelines for diagnosis and management. JAMA 2004291 228-238. (https://doi.org/10.1001/ jama.291.2.228)

27 Rodriguez-Gutierrez R, Maraka S, Ospina NS, Montori VM \& Brito JP. Levothyroxine overuse: time for an about face? Lancet: Diabetes and Endocrinology 20175 246-248. (https://doi.org/10.1016/S22138587(16)30276-5)

28 Taylor PN, Iqbal A, Minassian C, Sayers A, Draman MS, Greenwood R, Hamilton W, Okosieme O, Panicker V, Thomas SL et al. Falling threshold for treatment of borderline elevated thyrotropin levels - balancing benefits and risks: evidence from a large community-based study. JAMA Internal Medicine 2014174 32-39. (https://doi.org/10.1001/jamainternmed.2013.11312)

29 Fliers E, Bianco AC, Langouche L \& Boelen A. Thyroid function in critically ill patients. Lancet: Diabetes and Endocrinology 20153 816-825. (https://doi.org/10.1016/S2213-8587(15)00225-9)

30 Sawka AM, Cappola AR, Peeters RP, Kopp PA, Bianco AC \& Jonklaas J. Patient context and thyrotropin levels are important when considering treatment of subclinical hypothyroidism. Thyroid 2019 29 1359-1363. (https://doi.org/10.1089/thy.2019.0494)
31 Baldini IM, Vita A, Mauri MC, Amodei V, Carrisi M, Bravin S \& Cantalamessa L. Psychopathological and cognitive features in subclinical hypothyroidism. Progress in Neuro-Psychopharmacology and Biological Psychiatry 199721 925-935. (https://doi.org/10.1016/ s0278-5846(97)00089-4)

32 Jorde R, Waterloo K, Storhaug H, Nyrnes A, Sundsfjord J \& Jenssen TG. Neuropsychological function and symptoms in subjects with subclinical hypothyroidism and the effect of thyroxine treatment. Journal of Clinical Endocrinology and Metabolism 200691 145-153. (https://doi.org/10.1210/jc.2005-1775)

33 Chaker L, Baumgartner C, den Elzen WP, Ikram MA, Blum MR, Collet TH, Bakker SJ, Dehghan A, Drechsler C, Luben RN et al. \& Thyroid Studies Collaboration. Subclinical hypothyroidism and the risk of stroke events and fatal stroke: an individual participant data analysis. Journal of Clinical Endocrinology and Metabolism 2015100 2181-2191. (https://doi.org/10.1210/jc.2015-1438)

34 Gencer B, Collet TH, Virgini V, Bauer DC, Gussekloo J, Cappola AR, Nanchen D, den Elzen WP, Balmer P, Luben RN et al. Subclinical thyroid dysfunction and the risk of heart failure events: an individual participant data analysis from 6 prospective cohorts. Circulation 2012126 1040-1049. (https://doi.org/10.1161/ CIRCULATIONAHA.112.096024)

35 Chaker L, Bianco AC, Jonklaas J \& Peeters RP. Hypothyroidism. Lancet 2017390 1550-1562. (https://doi.org/10.1016/S0140-6736(17)30703-1)

36 Cappola AR. The thyrotropin reference range should be changed in older patients. JAMA 2019. (https://doi.org/10.1001/jama.2019.14728)

37 van de Ven AC, Netea-Maier RT, Smit JW, Kusters R, van der Stappen JW, Pronk-Admiraal CJ, Buijs MM, Schoenmakers CH, Koehorst SG, de Groot MJ et al. Thyrotropin versus age relation as an indicator of historical iodine intake. Thyroid 201525 629-634. (https://doi.org/10.1089/thy.2014.0574)

38 Somwaru LL, Arnold AM, Joshi N, Fried LP \& Cappola AR. High frequency of and factors associated with thyroid hormone overreplacement and under-replacement in men and women aged 65 and over. Journal of Clinical Endocrinology and Metabolism 200994 1342-1345. (https://doi.org/10.1210/jc.2008-1696)

39 Blum MR, Bauer DC, Collet TH, Fink HA, Cappola AR, da Costa BR, Wirth CD, Peeters RP, Åsvold BO, den Elzen WP et al. Subclinical thyroid dysfunction and fracture risk: a meta-analysis. JAMA 2015 313 2055-2065. (https://doi.org/10.1001/jama.2015.5161)

40 Razvi S, Peeters R \& Pearce SHS. Thyroid hormone therapy for subclinical hypothyroidism. JAMA 2019321 804-804. (https://doi. org/10.1001/jama.2018.20002)

41 Razvi S, Shakoor A, Vanderpump M, Weaver JU \& Pearce SH. The influence of age on the relationship between subclinical hypothyroidism and ischemic heart disease: a metaanalysis. Journal of Clinical Endocrinology and Metabolism 200893 2998-3007. (https:// doi.org/10.1210/jc.2008-0167)

42 Ernst FR, Barr P, Elmor R, Sandulli W, Thevathasan L, Sterman AB, Goldenberg J \& Vora K. The economic impact of levothyroxine dose adjustments: the CONTROL HE Study. Clinical Drug Investigation 201737 71-83. (https://doi.org/10.1007/s40261-016-0462-3)

43 Maher RL, Hanlon J \& Hajjar ER. Clinical consequences of polypharmacy in elderly. Expert Opinion on Drug Safety 201413 57-65. (https://doi.org/10.1517/14740338.2013.827660)

44 Dagli RJ \& Sharma A. Polypharmacy: a global risk factor for elderly people. Journal of International Oral Health 20146 i-ii.

45 Sawin CT, Geller A, Wolf PA, Belanger AJ, Baker E, Bacharach P, Wilson PW, Benjamin EJ \& D'Agostino RB. Low serum thyrotropin concentrations as a risk factor for atrial fibrillation in older persons. New England Journal of Medicine 1994331 1249-1252. (https://doi. org/10.1056/NEJM199411103311901)

46 Flynn RW, Bonellie SR, Jung RT, MacDonald TM, Morris AD \& Leese GP. Serum thyroid-stimulating hormone concentration and morbidity from cardiovascular disease and fractures in patients on 
long-term thyroxine therapy. Journal of Clinical Endocrinology and Metabolism 201095 186-193. (https://doi.org/10.1210/jc.2009-1625)

47 Brown T. Best-selling, most prescribed branded drugs through March. Medscape Medical News 2015100.

48 Asvold BO, Vatten LJ \& Bjoro T. Changes in the prevalence of hypothyroidism: the HUNT Study in Norway. European Journal of Endocrinology 2013169 613-620. (https://doi.org/10.1530/EJE-130459)

49 Greiver M, McIsaac W \& DelGiudice L. Patterns of thyroid screening and case detection in patients without thyroid disease in Canadian primary care (poster). In North American Primary Care Research Group - 2017 Practice-Based Research Network (PBRN) Conference, pp. 22-23, 2017.

50 LeFevre ML \& U.S. Preventive Services Task Force. Screening for thyroid dysfunction: US Preventive Services Task Force recommendation statement. Annals of Internal Medicine 2015162 641-650. (https://doi.org/10.7326/M15-0483)

$51 \mathrm{Chu}$ JW \& Crapo LM. The treatment of subclinical hypothyroidism is seldom necessary. Journal of Clinical Endocrinology and Metabolism 200186 4591-4599. (https://doi.org/10.1210/jcem.86.10.7961)

52 Boucai L, Hollowell JG \& Surks MI. An approach for development of age-, gender-, and ethnicity-specific thyrotropin reference limits. Thyroid 201121 5-11. (https://doi.org/10.1089/thy.2010.0092)
53 Brenta G, Vaisman M, Sgarbi JA, Bergoglio LM, Andrada NCd, Bravo PP, Orlandi AM, Graf H \& Task Force on Hypothyroidism of the Latin American Thyroid Society (LATS). Clinical practice guidelines for the management of hypothyroidism. Arquivos Brasileiros de Endocrinologia e Metabologia 201357 265-291. (https:// doi.org/10.1590/s0004-27302013000400003)

54 Rosario PW. Levothyroxine in subclinical hypothyroidism: a lifelong therapy? Clinical Endocrinology 201072 718-720. (https://doi. org/10.1111/j.1365-2265.2009.03711.x)

55 Rosario PW \& Calsolari MR. Levothyroxine therapy in the subclinical hypothyroidism: a lifelong therapy? A long-term study. Clinical Endocrinology 201685 819-820. (https://doi.org/10.1111/cen.13174)

56 Wasniewska M, Corrias A, Aversa T, Valenzise M, Mussa A, De Martino L, Lombardo F, De Luca F \& Salerno M. Comparative evaluation of therapy with L-thyroxine versus no treatment in children with idiopathic and mild subclinical hypothyroidism. Hormone Research in Paediatrics 201277 376-381. (https://doi. org/10.1159/000339156)

57 Radetti G, Salerno M, Guzzetti C, Cappa M, Corrias A, Cassio A, Cesaretti G, Gastaldi R, Rotondi M, Lupi F et al. Thyroid function in children and adolescents with Hashimoto's thyroiditis after L-thyroxine discontinuation. Endocrine Connections 20176 206-212. (https://doi.org/10.1530/EC-17-0023)

Received 5 June 2020

Revised version received 29 July 2020

Accepted 9 September 2020 